\title{
Role of triple fixed combination valsartan, amlodipine and hydrochlorothiazide in controlling blood pressure
}

REVIEW

This article was published in the following Dove Press journal:

Patient Preference and Adherence

29 April 2010

Number of times this article has been viewed

\author{
Monica Doménech \\ Antonio Coca \\ Hypertension Unit, Department \\ of Internal Medicine, Institute \\ of Internal Medicine and Dermatology, \\ Hospital Clinic (IDIBAPS), University \\ of Barcelona, Spain
}

\begin{abstract}
Hypertension is one of the main risk factors for the development of cardiovascular diseases and the search for new therapeutic strategies aimed at optimizing its control remains an ongoing research and clinical challenge. In recent years, there has been a marked increase in the use of combinations of antihypertensive drugs with complementary mechanisms of action, with the aims of reducing blood pressure levels more rapidly and vigorously than strategies employing monotherapy and improving treatment compliance and adhesion. Therefore, as recommended by the 2009 reappraisal of the European Society of Hypertension/European Society of Cardiology Guidelines, the use of a triple combination that combines a calcium channel blocker, an angiotensin II receptor blocker and a thiazide diuretic seems a reasonable and efficacious combination for the management of hypertensive patients with moderate, high or very high risk. This article reviews the clinical trials carried out with the fixed combination of amlodipine/valsartan/hydrochlorothiazide at the doses recommended for each drug in monotherapy. The data show that this combination achieved greater reductions in mean sitting diastolic and systolic blood pressure than amlodipine, valsartan or hydrochlorothiazide in monotherapy, with favorable pharmacodynamic and pharmacokinetic profiles. The triple combination at high single doses should be used with caution in elderly patients and those with renal or liver failure. Although the tolerability and safety of the triple combination are good, the mostfrequently reported adverse effects were peripheral edema, headache and dizziness. Analytical alterations were consistent with the already-known biochemical effects of amlodipine, valsartan or hydrochlorothiazide in monotherapy. In summary, triple-therapy with amlodipine/valsartan/ hydrochlorothiazide in a single pill contributes additional advantages to fixed -combinations of two drugs, achieving a greater and more rapid reduction in blood pressure levels in a safe, well-tolerated manner.
\end{abstract}

Keywords: hypertension treatment, antihypertensive fixed-dose triple-therapy, blood pressure control

\section{Introduction}

Hypertension affects millions of people worldwide and in developed countries the progressive aging of the population is increasing its prevalence even more. Hypertension is a determining risk factor for the development of cardiovascular diseases such as myocardial infarction, stroke, renal disease and heart failure and correct blood pressure (BP) control reduces cardiovascular morbidity and mortality. ${ }^{1}$ However, in spite of the many therapeutic options available and the social and health consequences associated with inadequate BP control, only one-third of hypertensive patients achieve correct BP levels according to their total cardiovascular risk. ${ }^{1}$
Hypertension Unit, Institute of Internal

Medicine and Dermatology (ICMiD),

Hospital Clinic, Villarroel I70,

08036 - Barcelona, Spain

Tel +34932275759

Fax +34932275724

Email acoca@clinic.ub.es 
Because the etiopathogenesis of hypertension is multifactorial, most patients require more than one antihypertensive drug to achieve correct $\mathrm{BP}$ control $^{2}$ and the most common therapeutic strategy is a fixed or free combination of two antihypertensive drugs. ${ }^{3}$ In patients with high or very high cardiovascular risk, such as diabetics or those with renal failure, a combination of three or more antihypertensive drugs with differing mechanisms of action is required to reach the BP objective recommended by the European Guidelines on Hypertension $(\mathrm{BP}<130 / 80) .{ }^{4}$ The use of antihypertensive combinations with complementary mechanisms of action results in greater BP reductions than those achieved by the sum of each drug in monotherapy. Therefore, the European guidelines consider the combined use of a calcium channel blocker, an angiotensin II receptor blocker and a thiazide diuretic a reasonable combination ${ }^{4}$ for patients with very-high baseline BP values or those at high cardiovascular risk.

Calcium channel blockers prevent the entry of calcium to the cellular cytosol in arteriolar smooth muscle cells. Angiotensin II receptor blockers impede the activation of angiotensin $\mathrm{II} \mathrm{AT}_{1}$ receptors, preventing the vasoconstriction induced by angiotensin II, while blockade of the receptor in the renal cells helps prevent the renal retention of sodium. Thiazide diuretics reduce intravascular volume and total body sodium. The final effect of the combination of these three different mechanisms of action not only provides antihypertensive synergy but simultaneously counteracts or attenuates the possible adverse effects of each drug in monotherapy, particularly the hypokalemia induced by the diuretic and the peripheral edema induced by the calcium antagonist. The different available fixed combinations of valsartan/hydrochlorothiazide (HCTZ) and valsartan/amlodipine have been shown to be efficient and safe in reducing BP levels in patients in whom monotherapy is not sufficient to achieve BP control. ${ }^{5,6}$ The possible use of triple therapy with amlodipine, valsartan and HCTZ in a single pill represents a step forward in improving the control of hypertension by making treatment simpler and thereby improving long-term adhesion and treatment persistence. ${ }^{7}$

This review briefly and concisely explains some pharmacodynamic and pharmacokinetic aspects of this triple therapy and synthesizes the results of the different clinical trials carried out using this fixed combination.

\section{Pharmacodynamic profile}

Valsartan is a powerful, specific angiotensin II $\mathrm{AT}_{1}$ receptor antagonist. In hypertensives, administration of a single oral dose of valsartan produces a reduction in BP that begins
2 hours after administration and reaches a peak at 4 to 6 hours. The antihypertensive effect persists for 24 hours after administration. When repeated doses are administered, the maximum reduction in BP is usually achieved in 2 to 4 weeks. ${ }^{8}$

Amlodipine inhibits the entry of calcium ions to the vascular smooth muscle of the resistance arterioles. The antihypertensive mechanism of action of amlodipine is due to a direct relaxant effect on the vascular smooth muscle, causing reductions in peripheral vascular resistance and BP. These effects are dependant on the movement of extracellular calcium ions to the interior of smooth muscle cells through specific ion channels. After administration of therapeutic doses to hypertensives, amlodipine causes vasodilation that induces a reduction in BP levels with no significant changes in the heart rate or plasma catecholamine levels. In hypertensive patients with normal kidney function, therapeutic doses of amlodipine are associated with a reduction in renal vascular resistance and increased glomerular filtration and renal plasma flow, with no modifications in the filtration rate or proteinuria. ${ }^{8}$

HCTZ is a diuretic that reduces the reabsorption of electrolytes in the renal tubule, increasing the excretion of sodium and chloride and, consequently, increasing plasma renin activity and aldosterone secretion, increasing urinary potassium loss and reducing serum potassium. ${ }^{8}$ Currently, no specifically designed studies have evaluated the pharmacodynamic characteristics of the triple combination. However, in spite of the lack of specific pharmacodynamic studies, the use of the fixed combination of amlodipine/valsartan/HCTZ is accepted, as the three products are all approved by the European Medicines Agency (EMEA) to treat hypertension in monotherapy and pharmacodynamic studies show no unfavorable interactions. ${ }^{9}$

\section{Pharmacokinetic profile}

The pharmacokinetic characteristics of amlodipine, valsartan or HCTZ in monotherapy or in combination at fixed doses (amlodipine/valsartan or valsartan/HCTZ) are well known. ${ }^{10,11}$ The three drugs exhibit linear pharmacokinetics. ${ }^{8}$

\section{Pharmacokinetics of the drugs in monotherapy}

The absorption of oral amlodipine is practically total and plasma concentrations increase gradually to reach a peak at 6 to 9 hours. Its bioavailability is $64 \%$ to $80 \%$, which is not modified by food ingestion. Ninety-four percent bonds with plasma proteins. ${ }^{12}$ It is metabolized in the liver by CYP $3 \mathrm{~A} 4$. 
The elimination of amlodipine from plasma occurs in two phases, with a half-life of 30 to 50 hours. Ten percent of the original amlodipine and $60 \%$ of amlodipine metabolites are excreted in urine. ${ }^{8}$

The absorption of oral valsartan is approximately $23 \%$, reaching a peak at 3 hours. Ninety percent bonds with plasma proteins, mainly serum albumin. Valsartan does not transform extensively since only approximately $20 \%$ of the dose is recovered as metabolites. It is mainly eliminated unaltered in the feces $(83 \%)$ and the urine $(13 \%) .{ }^{8}$ The half-life of valsartan is 6 hours. $^{6}$

The absorption of oral HCTZ is rapid, with a maximum serum concentration $\left(\mathrm{C}_{\max }\right)$ of approximately 2 hours. The increase in mean area under the serum concentration-time curve during the dosing interval (AUC) is linear and dosedependent within the therapeutic range. The bioavailability is $65 \%$ to $75 \%$. Food ingestion reduces bioavailability by $10 \%$ and peak concentration by $20 \%$, increasing the maximum time from 1.6 hours to 2.9 hours. More than ninety percent is eliminated unaltered in the urine.

\section{Pharmacokinetics of the triple combination}

After oral administration of the fixed combination of amlodipine/valsartan/HCTZ in fasting conditions, the peak plasma level of valsartan is reached in 3 to 4 hours, that of HCTZ in 1 to 3 hours and that of amlodipine in 6 to 9 hours. ${ }^{9}$ The elimination half-lives of valsartan, HCTZ and amlodipine are 13 to 23 hours, 10 to 12 hours and 41 to 47 hours, respectively. ${ }^{9}$

The absorption of amlodipine/valsartan/HCTZ is similar to the individual administration of each of its components in terms of bioequivalence and bioavailability. Five studies have evaluated the bioavailability and bioequivalence of amlodipine/valsartan/HCTZ and the effect of food ingestion on them. ${ }^{8}$ The VEA489A2305 study analyzed the bioequivalence of amlodipine/valsartan/HCTZ at doses of $5 / 160 / 12.5 \mathrm{mg}$, respectively. With a confidence interval (CI) of $90 \%$ the ratio of the geometric mean for $\mathrm{AUC}_{0-\mathrm{t}}, \mathrm{AUC}_{0-\infty}$, $\mathrm{C}_{\max }$ was 0.8 to 1.25 indicating that the rate and extent of absorption of amlodipine/valsartan/HCTZ are similar to administration of each drug in monotherapy. Likewise, the VEA489A2306 study, which analyzed the bioequivalence of a dose of 5/160/25 mg, respectively, found a similar range of bioequivalence. The subsequent VEA489A2105 and VEA489A2106 studies analyzed the bioequivalence of 5 and $10 \mathrm{mg}$ of amlodipine in the United States formulation versus the Norvasc ${ }^{\circledR}$ formulation, and both studies found a range of $\mathrm{AUC}_{0-\mathrm{t}}, \mathrm{AUC}_{0-\infty}, \mathrm{C}_{\max }$ of 0.8 to 1.25. Comparison between amlodipine/valsartan/HCTZ 10/160/25 mg and amlodipine/valsartan/HCTZ 10/160/12.5 mg showed no differences in bioequivalence and bioavailability. The combination of amlodipine/valsartan/HCTZ at a maximum dose of 10/320/25 mg showed similar linear and dose proportional pharmacokinetics to the dose of 5/160/12.5 mg, whose bioequivalence was clearly established in the previous trials.

The effect of ingestion on the bioavailability of amlodipine/ valsartan/HCTZ 10/320/25 mg at fixed doses in healthy subjects was evaluated in the CVEA 489A2310 clinical trial, a randomized, open-label, single-dose, two-period crossover study. Eighteen subjects were randomized to the fixed combination of a single oral dose of amlodipine/ valsartan/HCTZ administered under fasting or fed conditions. The results showed that the $\mathrm{C}_{\max }$ of valsartan increased by $12 \%$ and $\mathrm{AUC}_{0-\mathrm{t}}, \mathrm{AUC}_{0-\infty}, \mathrm{C}_{\max }$ increased by $14 \%$ after ingestion in comparison with fasting conditions. The upper limit of 90\% CI for both $\mathrm{C}_{\max }$ and AUC was between 1.25 and 1.32. Likewise, the bioavailability of amlodipine, valsartan and HCTZ is similar under fed and fasting conditions following a single oral dose administration of $10 \mathrm{mg} / 320 \mathrm{mg} / 25 \mathrm{mg}$ of the amlodipine/valsartan/HCTZ fixed combination tablet. With respect to the pharmacokinetic interaction between amlodipine, valsartan and HCTZ, the VEA489A2104 study in hypertensive patients found that the addition of valsartan to the amlodipine/HCTZ combination increased the AUC of HCTZ by $8 \%$ and decreased the $\mathrm{C}_{\max }$ by $17 \%$. The addition of valsartan to the amlodipine/HCTZ fixed combination increased the AUC and $\mathrm{C}_{\max }$ of amlodipine by $9 \%$ and $10 \%$, respectively, with a $\mathrm{CI}$ of $80 \%$ to $125 \%$.

The addition of HCTZ to the fixed combination of amlodipine/valsartan increased the $\mathrm{AUC}$ and $\mathrm{C}_{\max }$ of valsar$\tan$ by $25 \%$ and $22 \%$, respectively, although the geometric mean ratios for amlodipine exposure were not within the $80 \%$ to $125 \%$ range. Finally, the addition of amlodipine to the valsartan/HCTZ fixed combination increased the AUC of valsartan by $10 \%$ and the $\mathrm{C}_{\max }$ by $15 \%$ and increased the AUC of HCTZ by $3 \%$ and the $\mathrm{C}_{\max }$ by $2 \%$, with $90 \%$ CI within the $80 \%-125 \%$ range. In conclusion, there are no pharmacokinetic interactions and therefore the safety and efficacy of the triple fixed dose combination of amlodipine/valsartan/HCTZ is sufficiently demonstrated in phase III efficacy studies.

\section{Special subgroups}

\section{Children and adolescents}

There are no pharmacokinetic data for people aged $<18$ years. 


\section{Elderly patients ( $\geq 65$ years)}

The peak plasma concentration time of amlodipine is similar in young patients and the elderly, although in the elderly amlodipine clearance tends to decline, causing an increase in AUC of around $>70 \%$; therefore, caution should be used when increasing the dose. ${ }^{8}$ The systemic exposure of valsartan is slightly higher in the elderly in comparison with young people, although no clinical significance has been demonstrated. There is little data on the systemic clearance of HCTZ, which decreases in both the healthy and hypertensive elderly.

\section{Renal failure}

The pharmacokinetics of amlodipine are not significantly affected by renal failure and therefore patients with a glomerular filtration rate $>30 \mathrm{~mL} /$ minute may receive the normal starting dose. ${ }^{8}$

\section{Liver failure}

Patients with liver failure have reduced clearance of amlodipine, increasing the AUC by $40 \%$ to $60 \%$. The mean half-life of valsartan in patients with mild-to-moderate chronic liver disease is double that found in healthy volunteers. Therefore, it should be used with caution in patients with liver failure.

\section{Clinical efficacy studies}

Clinical trials in patients with hypertension and other cardiovascular risk factors or comorbidities have shown the efficacy of strategies based on amlodipine, ${ }^{10}$ valsartan ${ }^{11}$ or HCTZ in the reduction of cardiovascular morbidity and mortality. Two completed clinical trials, the VEA A2302 and VEA ABR01 studies, were designed to evaluate the efficacy and safety of amlodipine/valsartan/HCTZ in combination, although the VEA ABR01 study found no significant evidence with respect to clinical efficacy. The most representative trial is the recently published Triple Antihypertensive Therapy with Amlodipine, Valsartan and Hydrochlorothiazide: A randomized clinical trial (VEA A2302). ${ }^{13}$

\section{VEA A2302 study 13}

This was a multinational, randomized, double-blind study in parallel groups. Patients aged 18 to 85 years with moderate-severe hypertension (grades 2-3) with mean sitting diastolic blood pressure (MSDBP) $\geq 100 \mathrm{mmHg}$ and mean sitting systolic blood pressure (MSSBP) $\geq 145 \mathrm{mmHg}$ were included. Patients had to discontinue antihypertensive treatment for one week, during which they received placebo. Patients with severe hypertension
(MSSBP $\geq 180 \mathrm{mmHg}$ or MSDBP $\geq \mathrm{Hg} 110 \mathrm{mmHg}$ ) were randomized immediately to active treatment. Patients who did not fulfil inclusion criteria 7 days after ceasing previous treatment continued with placebo for 2 to 3 weeks and were randomized if MSSBP $\geq 145 \mathrm{mmHg}$ and MSDBP $\geq 100 \mathrm{mmHg}$ were achieved. Patients with MSSBP $\geq 200$ $\mathrm{mmHg}$ or MSDBP $\geq 120 \mathrm{mmHg}$ were excluded. Patients receiving $\geq 4$ antihypertensive drugs in the screening visit, or $\geq 3$ antihypertensive drugs with MSSBP/MSDBP $\geq 140 / 90 \mathrm{mmHg}$, or $\geq 2$ antihypertensive drugs with MSSBP/MSDBP $\geq 180 / 110 \mathrm{mmHg}$ were also excluded.

Other exclusion criteria were a history of hypersensitivity to one of the three drugs in monotherapy, a history of hypertensive encephalopathy, stroke, transient ischemic accidents, myocardial infarction or any other type of revascularization, second or third degree heart block, angina pectoris, significant arrhythmia or valvular alteration; uncontrolled type 1 or type 2 diabetes, hepatic, renal or pancreatic disease or need for any other medication that might interfere in BP control.

Of the 4285 patients enrolled in 15 countries, only 2271 were randomized to double-blind treatment after a single-blind placebo run-in period for a maximum of 4 weeks, followed by active treatment for 8 weeks. After receiving instructions on BP self-measurement, patients were provided with a semi-automatic OMRON apparatus (model HEM705CP) for home determination of systolic $\mathrm{BP}$ and diastolic BP twice daily during the placebo period. Patients with MSSBP $\geq 145 \mathrm{mmHg}$ and $<200 \mathrm{mmHg}$ and MSDBP $>100 \mathrm{mmHg}$ and $<120 \mathrm{mmHg}$ were randomized (1:1:1:1) to one of the four treatment arms: amlodipine/valsartan/HCTZ 10/320/25 mg, valsartan/ HCTZ 320/25 mg, amlodipine/valsartan $10 / 320 \mathrm{mg}$ or amlodipine/HCTZ 10/25 mg all once daily.

Patients underwent a 2-stage forced-titration period starting with lower doses of study medication for the two first weeks post randomization. From the third week to the end of the study at 6 weeks, all patients reached the maximum dose to which they had been randomized.

The primary study objective was to evaluate the efficacy and safety of the "high-dose" triple combination amlodipine/valsartan/HCTZ 10/320/25 mg in comparison with each of the components in double therapy (valsartan/ HCTZ 320/25 mg, amlodipine/valsartan $10 / 320 \mathrm{mg}$ or amlodipine/HCTZ 10/25 mg) in patients with severemoderate hypertension. The secondary objectives were to evaluate the number of patients who achieved MSSBP/ MSDBP $<140 / 90 \mathrm{mmHg}$, the number of responders for diastolic BP (MSDBP $<90 \mathrm{mmHg}$ and/or $\geq 10 \mathrm{mmHg}$ with 
respect to baseline DBP values), the number of responders for SBP (MSBPP $<140 \mathrm{mmHg}$ and/or $\geq 15 \mathrm{mmHg}$ with respect to baseline SBP, and the reduction in systolic and diastolic mean BP by 24 hour ambulatory BP monitoring (ABPM).

Of the 2271 randomized patients, 2060 completed the study. The main causes of discontinuation in the placebo run-in period were not to require the study drug any longer (28.1\%), abnormal test procedure results $(6.9 \%)$ and withdrawal of consent $(5.3 \%)$. In the randomized group, the main causes of discontinuation were adverse effects $(3.1 \%)$, withdrawal of informed consent $(2.5 \%)$ and loss to follow-up (1.5\%).

There were no differences in baseline characteristics between the two groups. Nearly $72 \%$ of randomized patients were Causcasians and 55\% were male, with a mean age of 53 years ( $14 \%$ aged $\geq 65$ years). Baseline MSSBP/MSDBP was $169.9 / 106.5 \mathrm{mmHg}$. Approximately $10 \%$ of patients were diabetic. Previous hypertensive treatment included angiotensin converting enzyme inhibitors in $30.2 \%$, dihydropyridine derivatives in $18.1 \%$, thiazide diuretics in $17.3 \%$, angiotensin II receptor blockers in $16.4 \%$ and beta-blockers in $12.5 \%$.

Table 1 summarizes the results of the primary objective. Significant reductions in MSDBP and MSSBP were observed in comparison with baseline values in the four treatment arms, although the greatest reductions were observed in the amlodipine/valsartan/HCTZ group. The greatest antihypertensive effect was observed from the third week of treatment onwards in all treatment arms. Comparison of the antihypertensive efficacy of the four pharmacological combinations showed that amlodipine/valsartan/HCTZ 10/320/25 mg achieved significantly higher reductions than those obtained with valsartan/HCTZ 320/25, amlodipine/valsartan 10/320 and amlodipine/HCTZ 10/25 (Table 2). These differences were maintained after adjustment for race, sex and age.

With respect to the secondary objectives, significantly higher proportions of patients treated with triple therapy reached overall BP control (defined as MSSBP/ MSDBP $<140 / 90 \mathrm{mmHg}$ ), diastolic control rates and systolic control rates. Likewise, the rate of responders for both SBP and DBP was also significantly higher in patients randomized to the triple therapy. Finally, reductions in BP measured by ABPM were clinically and statistically higher in the triple therapy arm compared with all three dual therapies.

\section{VEA ABROI study 9}

This was a multicenter, randomized, parallel double-blind study which included hypertensive patients aged $\geq 18$ years in stable treatment with $>2$ antihypertensive drugs during the last two months. The main end point of the study was to evaluate the proportion of patients who reached BP control after 12 weeks of treatment. Of the 264 patients who received amlodipine/valsartan/HCTZ, 61\% reached the control objective (intention-to-treat). The percentage of control was similar in the treatment arms: $43.9 \%$ for amlodipine/valsartan/HCTZ10/160/12.5 mg and 45.8\% for amlodipine/valsartan/HCTZ 5/160/25 mg. However, the main limitation of this study was that it was not designed to compare antihypertensive strategies. ${ }^{9}$

\section{VAA A220IEI study 9}

This was a multicenter, double-blind, open label extension study lasting 52 weeks in 2201 patients with mild-moderate

Table I Within-treatment analyses for change from baseline to endpoint in mean sitting BP (ITT population)

\begin{tabular}{|c|c|c|c|c|}
\hline Treatment & $\mathbf{N}$ & $\begin{array}{l}\text { Mean change from } \\
\text { baseline (SE) }\end{array}$ & $\begin{array}{l}95 \% \mathrm{Cl} \text { for mean } \\
\text { change from baseline }\end{array}$ & $P$ value \\
\hline \multicolumn{5}{|l|}{ Diastolic BP } \\
\hline AML/VAL/HCTZ I0/320/25 & 571 & $-24.57(0.395)$ & $(-25.348-23.797)$ & $<0.000$ I $^{*}$ \\
\hline VAL/HCTZ 320/25 & 553 & $-19.40(0.431)$ & $(-20.250-18.558)$ & $<0.000$ I $^{*}$ \\
\hline AML/VAL I0/320 & 558 & $-21.4 \mathrm{I}(0.394)$ & $(-22.186-20.639)$ & $<0.000 I^{*}$ \\
\hline AML/HCTZ I0/25 & 554 & $-19.60(0.407)$ & $(-20.399-18.801)$ & $<0.000 I^{*}$ \\
\hline \multicolumn{5}{|l|}{ Systolic BP } \\
\hline AML/VAL/HCTZ I0/320/25 & 571 & $-39.37(0.962)$ & $(-40.725-38.08)$ & $<0.000$ I $^{*}$ \\
\hline VAL/HCTZ 320/25 & 553 & $-31.81(0.739)$ & $(-33.265-30.362)$ & $<0.000 I^{*}$ \\
\hline AML/VAL I0/320 & 558 & $-33.37(0.660)$ & $(-34.668-32.077)$ & $<0.000 I^{*}$ \\
\hline AML/HCTZ I0/25 & 554 & $-31.86(0.710)$ & $(-33.264-30.475)$ & $<0.000$ I $^{*}$ \\
\hline
\end{tabular}

*Indicates statistical significance $\leq 0.05$.

Data obtained from the VEA A2302 Study. ${ }^{13}$

Abbreviations: ITT, intention to treat; AML, amlodipine; VAL, valsartan; HCTZ, hydrochlorothiazide. 
Table 2 Between-treatment comparisons for change from baseline to endpoint in mean sitting BP (MSBP) (mmHg)

\begin{tabular}{|c|c|c|c|c|}
\hline Treatment & $\begin{array}{l}\text { LSM change from } \\
\text { baseline }\end{array}$ & $\begin{array}{l}\text { LSM difference in change } \\
\text { from baseline (SE) }\end{array}$ & $P$ value & $\begin{array}{l}\text { Hochberg adjusted } \\
P \text { value }\end{array}$ \\
\hline \multicolumn{5}{|l|}{ Diastolic BP } \\
\hline AML/VAL/HCTZ I0/320/25 & -24.74 & & & $<0.000 I^{*}$ \\
\hline VAL/HCTZ 320/25 & -19.69 & $-5.05(0.539)$ & $<0.0001$ & \\
\hline AML/VAL $10 / 320$ & -21.49 & $-3.25(0.537)$ & $<0.001+$ & \\
\hline AML/HCTZ I0/25 & -19.46 & $-5.28(0.539)$ & $<0.0001$ & \\
\hline \multicolumn{5}{|l|}{ Systolic BP } \\
\hline AML/VAL/HCTZ I0/320/25 & -39.68 & & & $<0.000 I^{*}$ \\
\hline VAL/HCTZ 320/25 & -32.04 & $-7.64(0.848)$ & $<0.0001$ & \\
\hline AML/VAL I0/320 & -33.5 & $-6.18(0.846)$ & $<0.00 I^{* *}$ & \\
\hline AML/HCTZ I0/25 & -31.48 & $-8.20(0.848)$ & $<0.0001$ & \\
\hline
\end{tabular}

Notes: The Hochberg adjusted $P$ values are based on the maximum $P$ value for the three comparisons in MSDBP and the maximum $P$ value for the three comparisons in MSSBP.

*Indicates statistical significance $P \leq 0.05$.

**Maximum $P$ values of the three comparisons.

Adapted with permission from Calhoun DA, Lacourciere Y, ChiangTY, Glazer RD. Triple antihypertensive therapy with amlodipine, valsartan and hydrochlorothiazide:A randomized clinical trial. Hypertension. 2009;54:32-39.'3 Copyright (C) 2009 Lippincott,Williams \& Wilkins.

Abbreviations: LSM, least squares mean; AML, amlodipine; VAL, valsartan; HCTZ, hydrochlorothiazide.

hypertension who were randomized to receive amlodipine/valsartan $2.5 / 80 \mathrm{mg}$ or $5 / 80 \mathrm{mg}$ for 8 weeks. The dose was later increased to amlodipine/valsartan $5 / 160$ or $10 / 160 \mathrm{mg}$, with the option of adding HCTZ $12.5 \mathrm{mg}$ if BP control was inadequate. However, since the number of patients who required HCTZ was far below those who received dual therapy, this study can only be used for safety evaluation but does not support the efficacy of the triple combination of amlodipine/valsartan/HCTZ. ${ }^{9}$

\section{Safety and tolerability studies}

Although a reasonable number (1789) of patients have been treated with the triple combination of amlodipine/valsartan/
HCTZ, most information on safety and tolerability comes from the VEA A2302 study. ${ }^{13}$ The number of patients treated with high doses of this combination or treated for more than 6 months is limited. There are also few data on people aged $>65$ years and subgroups such as type 1 diabetics, badly controlled type 2 type diabetics, and patients with pre-existing heart disease or renal failure (creatinine $\geq 1.5$ ). ${ }^{13}$

In the VEA A2302 study, the frequency of patients with $>1$ adverse effect (AE) was similar in the four treatment arms, with a proportion of between $45 \%$ and $48 \%$. Most adverse effects were classified as mild-moderate. The

Table 3 Adverse events, regardless of study drug relationship, by preferred term and treatment

\begin{tabular}{|c|c|c|c|c|c|}
\hline & $\begin{array}{l}\text { AML/VAL/HCTZ } \\
10 / 320 / 25 \mathrm{mg}(\mathrm{n}=582)\end{array}$ & $\begin{array}{l}\text { VAL/HCTZ } \\
320 / 25 \mathrm{mg}(\mathrm{n}=559)\end{array}$ & $\begin{array}{l}\text { AML/VAL } \\
10 / 320(n=566)\end{array}$ & $\begin{array}{l}\text { AML/HCTZ } \\
10 / 25 \mathrm{mg}(\mathrm{n}=561)\end{array}$ & $\begin{array}{l}\text { Total } \\
(n=2268)\end{array}$ \\
\hline Preferred term & $\mathrm{N}(\%)$ & $\mathrm{N}(\%)$ & $\mathrm{N}(\%)$ & $N(\%)$ & $N(\%)$ \\
\hline Any preferred term & $263(45.2)$ & $253(45.3)$ & $254(44.9)$ & $27 \mid(48.3)$ & $104 \mid(45.9)$ \\
\hline Dizziness & $45(7.7)$ & $39(7)$ & $13(2.3)$ & $22(3.9)$ & $119(5.2)$ \\
\hline Peripheral edema & $26(4.5)$ & $5(0.9)$ & $48(8.5)$ & $50(8.9)$ & $129(5.7)$ \\
\hline Headache & $25(4.3)$ & $30(5.4)$ & $28(4.9)$ & $39(7)$ & $122(5.4)$ \\
\hline Dyspepsia & I3 (2.2) & $5(0.9)$ & $6(1.1)$ & $2(0.4)$ & $26(1.1)$ \\
\hline Fatigue & $13(2.2)$ & $15(2.7)$ & $12(2.1)$ & $8(1.4)$ & $48(2.1)$ \\
\hline Muscle spasms & $13(2.2)$ & $7(1.3)$ & $7(1.2)$ & $5(0.9)$ & $32(1.4)$ \\
\hline Back pain & $12(2.1)$ & $13(2.3)$ & $5(0.9)$ & $12(2.1)$ & $42(1.9)$ \\
\hline Nasopharyngitis & $12(2.1)$ & $13(2.3)$ & $13(2.3)$ & $12(2.1)$ & $50(2.2)$ \\
\hline Nausea & $12(2.1)$ & $7(1.3)$ & $10(1.8)$ & $12(2.1)$ & $4 \mid(1.8)$ \\
\hline
\end{tabular}

Reproduced with permission from Calhoun DA, Lacourciere Y, Chiang TY, Glazer RD. Triple antihypertensive therapy with amlodipine, valsartan and hydrochlorothiazide: A randomized clinical trial. Hypertension. 2009;54:32-39. ${ }^{13}$ Copyright (C) 2009 Lippincott, Williams \& Wilkins.

Abbreviations: AML, amlodipine; VAL, valsartan; HCTZ, hydrochlorothiazide. 
most common adverse effects (Table 3) were peripheral edema (5.7\%), headache (5.4\%) and dizziness (5.2\%). Dizziness occurred more frequently in the triple therapy $(7.7 \%)$ and in the dual combination of valsartan/HCTZ (7\%) compared with the dual combinations of amlodipine/ valsartan $(2.3 \%)$ or amlodipine/HCTZ (3.9\%). Peripheral edema, however, was more common in patients receiving amlodipine/HCTZ (8.9\%) or amlodipine/valsartan (8.5\%) than in those treated with the triple combination $(4.5 \%)$ or valsartan/HCTZ (0.9\%) (Table 4). Three percent of adverse effects were classified as severe, and the distribution was similar in all four treatment arms. Adverse effects potentially associated with reductions in BP were very infrequent. Hypotension was most frequently reported in patients receiving triple therapy $(1.5 \%)$ and the valsartan/HCTZ $(1.4 \%)$ combination. Other symptoms, such as fainting $(\leq 1 \%)$, postural instability or orthostatic hypotension were infrequent. ${ }^{9}$

In the longest study (2201E1) the most common adverse effects reported were peripheral edema, nasopharyngitis, dizziness, headache and back pain. The incidence of edema was $17 \%$ for the high dose combination and $9.7 \%$ for the low dose combination. ${ }^{9}$ No deaths were reported in any of the studies. Seventy-six percent of patients reporting severe adverse effects required hospitalization. ${ }^{13}$ Analytical alterations were consistent with the known biochemical effects of amlodipine, valsartan or HCTZ. There was an increase in blood urea in all arms, which was greater in the triple combination and in the valsartan/HCTZ combination. Increased creatinine, uric acid and calcium were observed in patients who received HCTZ. Serum potassium decreased in all arms including HCTZ; the reduction was greatest in the amlodipine/HCTZ combination $(-0.39 \mathrm{mmol} / \mathrm{L})$ and smallest in the amlodipine/valsartan/

Table 4 Comparison of occurrence of peripheral edema between treatment groups

\begin{tabular}{llll}
\hline $\begin{array}{l}\text { Treatment } \\
\text { comparison } \\
\text { (A vs B) }\end{array}$ & $\begin{array}{l}\text { Treatment A } \\
\mathbf{n} / \mathbf{N} \text { (\%) }\end{array}$ & $\begin{array}{l}\text { Treatment B } \\
\mathbf{n} / \mathbf{N}(\%)\end{array}$ & P value \\
\hline $\begin{array}{l}\text { AML/NAL/HCTZ } \\
\text { I0/320/25 vs }\end{array}$ & $26 / 582(4.5)$ & $5 / 559(0.9)$ & 0.0002 \\
VAL/HCTZ 320/25 & & & \\
AML/VAL/HCTZ & $26 / 582(4.5)$ & $48 / 566(8.5)$ & 0.0057 \\
I0/320/25 vs & & & \\
AML/VAL I0/320 & & $50 / 561(8.9)$ & 0.0029 \\
AML/VAL/HCTZ & $26 / 582(4.5)$ & & \\
I0/320/25 vs & & & \\
AML/HCTZ I0/25 & & & \\
\hline
\end{tabular}

Data obtained from the VEA A2302 Study. ${ }^{13}$

Abbreviations: AML, amlodipine; VAL, valsartan; HCTZ, hydrochlorothiazide.
HCTZ $(-0.16 \mathrm{mmol} / \mathrm{L})$ and valsartan/HCTZ $(-0.08 \mathrm{mmol} / \mathrm{L})$ combinations. ${ }^{9}$

In general, there was a lower incidence of adverse effects in people aged $\geq 65$ years than in younger people in the triple combination group, although only $14 \%$ of patients included in the VEA A2302 study were aged $\geq 65$ and only 14 patients $(2.2 \%)$ were aged $>75$ years. ${ }^{9}$ Only $3 \%$ of patients in the VEA A2302 trial discontinued the study, mainly due to dizziness and hypotension, with an incidence of $1 \%$ and $0.7 \%$ in the triple and dual combination groups, respectively, effects that were attributed a priori to the greater antihypertensive efficacy of the triple combination with respect to the dual combinations.

There are no data on the amlodipine/valsartan/HCTZ fixed combination in pregnant women, although according to the recommendations for each drug in monotherapy, triple therapy is not advised in the first trimester of gestation and is contraindicated in the second and third trimesters. ${ }^{9}$

\section{Future perspectives of triple fixed combinations}

Currently, although there are a large number of antihypertensive drugs and fixed combinations of two drugs, there are, in general, no large differences in their efficacy in reducing BP when administered in monotherapy. Only 30\% to $40 \%$ of hypertensive patients achieve BP control with a single drug. ${ }^{14}$ Many clinical trials on the efficacy of hypertensive treatment have shown the necessity to associate different antihypertensive drugs to reach BP control according to total cardiovascular risk. This evidence is collected in the 2007 Guidelines of the European Society of Hypertension/ European Society of Cardiology, and is confirmed and reinforced by the very-recent reappraisal of guidelines by the European Society of Hypertension. ${ }^{15}$ The ESH/ESC guidelines promote the use of fixed combinations as the frontline antihypertensive strategy in patients with very high $\mathrm{BP}$ or in those with high cardiovascular risk, in whom a rapid reduction in BP is desirable. ${ }^{15}$

The vast majority of essential hypertensive patients will require two or more antihypertensive drugs to achieve blood pressure targets. ${ }^{16}$ In addition, the recent ESH reappraisal of the European guidelines states that the best combinations for hypertension treatment are combinations of agents blocking the rennin-angiotensin system with thiazide diuretics or calcium channel blockers, and the combination of all three drugs when needed. Therefore, the use of these three components in a single pill taken in the morning seems a reasonable choice for many patients 
with moderate-severe high risk hypertension. An alpha or beta-blocker may be added to this baseline strategy when needed due to comorbidities or to achieve blood pressure control. ${ }^{15}$ The possibility of giving three drugs in a single tablet instead of three tablets will improve adherence to the therapeutic strategy, the quality of life and treatment persistence in the long term. In addition, the cost of the combination is often less expensive than buying each drug individually. ${ }^{17}$

Triple combination therapy with amlodipine/valsartan/ HCTZ in a single tablet should be administered once daily with or without food. The highest recommended dose is $10 / 320 / 25 \mathrm{mg}^{8}{ }^{8}$ It is contraindicated in patients with severe renal failure (creatinine clearance $<30 \mathrm{~mL} / \mathrm{min}$ ), severe liver failure, during the second and third trimesters of pregnancy, and in cases of refractory hypokalemia, hyponatremia, hypercalcemia and symptomatic hyperuricemia. Caution is recommended in patients with mildmoderate liver failure, heart failure and coronary disease and in elderly patients in whom the maximum dose of $10 / 320 / 25 \mathrm{mg}$ is not recommendable. There are no data to support the indication of amlodipine/valsartan/HCTZ in pediatric patients. ${ }^{8}$ Finally, drug interactions have not been explicitly evaluated, although the interactions known for the individual components are attributed to the triple combination. ${ }^{8}$ Logically, the triple fixed-dose combination of amlodipine/valsartan/HCTZ may increase the hypotensive effects of other antihypertensive drugs the patient may be taking. ${ }^{8}$

\section{Summary and conclusions}

The prevalence of hypertension in Europe is approximately $20 \%$ to $30 \%$ in the third/fourth decade of life and increases to $>70 \%$ in people aged $\geq 65$ years. ${ }^{9}$ Most patients require pharmacological combinations to achieve BP control. ${ }^{9}$ The combination of three drugs with synergistic and complementary mechanisms of action is a reasonable option for the management and control of moderate to severe hypertension. This article has reviewed the current evidence on the antihypertensive efficacy and safety of the triple combination of amlodipine/valsartan/HCTZ at both low and maximum doses. The efficacy of the triple combination is superior to that of its components in monotherapy or in dual combination. The tolerability and safety are good with only mild to moderate adverse effects in most cases, whose frequency is similar or inferior to that of its components in monotherapy. The main benefit of this triple combination in one tablet is to improve treatment adherence and compliance in order to achieve the therapeutic objective rapidly and efficiently. ${ }^{12}$ It is proven that delaying BP control by strategies of staggered dose increases is a risk factor for cardiovascular events in comparison with the initial use of combinations. ${ }^{16}$

In conclusion, the availability of a combination of three antihypertensive drugs in a single tablet contributes additional advantages to dual combinations, allowing more rapid and effective BP control in patients with moderate-severe hypertension or high cardiovascular risk. This is undoubtedly the right path to increase treatment adherence, improve compliance and reduce the morbidity and mortality associated with inadequate BP control.

\section{Disclosures}

The authors disclose no conflicts of interest.

\section{References}

1. Ong KL, Cheung BM, Man YB, Lau CP, Lam HS. Prevalence, awareness, treatment, and control of hypertension among United States adults (1999-2004). Hypertension. 2007;49:69-75.

2. Milani RV. Reaching for aggressive blood pressure goals: Role of angiotensin receptor blockade in combination therapy. Am J Manag Care. 2005;11(7 Suppl):S220-S227.

3. Cusham WC, Ford CE, Cutler JA, et al. Success and prediction of blood pressure control in diverse North American Settings: the hypertensive and lipid lowering treatment to prevent heart attack trial (ALLHAT). J Clin Hypertens. 2002;4:393-404.

4. Mancia G, De Backer G, Dominiczak A, Cifkova R, Fagard R, Germano G, et al. Guidelines for the Management of arterial hypertension: The Task Force for the management of arterial hypertension of the European Society Hypertension (ESH) and the European Society of Cardiology (ESC). J Hypertens. 2007;25:1105-1187.

5. Alleman Y, Fraile B, Lambert M, Barbier M, Ferber P, Izzo JL Jr. Efficacy of the combination of amlodipine and valsartan in patients with uncontrolled hypertension with previous monotherapy: The Exforge in previous failure after single therapy (EX-fast) study. J Clin Hypertens. 2008;10:185-194.

6. Pool JL, Glazer R, Weinberger M, Alvarado M, Huang J, Graff A. Comparison of valsartan/hydrochlorothiazide combination therapy at doses up to 320/25 versus monotherapy: a double blind placebo controlled study followed by long-term combination therapy in hypertensive adults. Clin Ther. 2007;29:61-73.

7. Dezii CM. A retrospective study of persistence with single pill combination therapy vs concurrent two pill therapy in patients with hypertension. Manag Caree. 2000;9(9 Suppl):2-6.

8. Product information. http://www.emea.europea.eu

9. Assessment report for Exforge HCT. International non-proprietary name: amlodipine besylate/valsartan/hydrochlorothiazide). http://www. emea.europea.eu

10. European Medicines Agency (EMEA). Summary of product characteristics: Exforge ${ }^{\circledR}$ (Amlodipine/Valsartan) filmcoated tablets. http://www.emea.europea.eu

11. EuropeanMedicines Agency (EMEA). Summary of product characteristics: Co-diovan ${ }^{\circledR}$ (Valsartan/Hydrochlorothiazide). http://www.emea. europea.eu

12. Plosker GL, Robinson DM. Amlodipine/valsartan fixed dose combination in hypertension. Drugs. 2008;68:373-381.

13. Calhoun DA, Lacourciere Y, Chiang TY, Glazer RD. Triple antihypertensive therapy with amlodipine, valsartan and hydrochlorothiazide: A randomized clinical trial. Hypertension. 2009;54:32-39. 
14. Elijovich F, Laffer C. A role for single pill triple-therapy in hypertension. Ther Adv Cardiovasc Dis. 2009;3:231-240.

15. Mancia G, Laurent S, Agabiti-Rosei E, Ambrosioni E, Burnier M, Caulfield MJ, et al. Reappraisal of European guidelines on hypertension management: A European Society of Hypertension Task Force document. J Hypertens. 2009;27:2121-2157.
16. Nasser SA, Lai Z, O’Connor S, Liu X, FlacK JM. Does earlier attainment of blood pressure goal translate into fewer cardiovascular events? Curr Hypertens Rev. 2008;10:398-404.

17. Black HR. Triple fixed-dose combination therapy: back to the past? Hypertension. 2009;54:19-22.

\section{Publish your work in this journal}

Patient Preference and Adherence is an international, peer-reviewed, open access journal that focusing on the growing importance of patient preference and adherence throughout the therapeutic continuum. Patient satisfaction, acceptability, quality of life, compliance, persistence and their role in developing new therapeutic modalities and compounds to optimize clinical outcomes for existing disease states are major areas of interest. This journal has been accepted for indexing on PubMed Central. The manuscript management system is completely online and includes a very quick and fair peer-review system. Visit http://www.dovepress.com/ testimonials.php to read real quotes from published authors.

\footnotetext{
Submit your manuscript here: http://www.dovepress.com/patient-preference-and-adherence-journal
} 